ISSN: $1130-3743$

DOI: http://dx.doi.org/10.14201/teoredu2014261163182

\title{
LA «CULTURA HIP HOP»: REVISIÓN DE SUS POSIBILIDADES COMO HERRAMIENTA EDUCATIVA
}

\author{
"Hip hop culture": a review of its potential \\ as an educational tool
}

\section{"Culture hip hop": analyse de son potentiel comme un outil pédagogique}

\begin{abstract}
Alberto Rodríguez Álvarez y Lucía Iglesias da CunHA
Universidad de Santiago de Compostela. Facultad de Ciencias de la Educación.

Departamento de Teoría de la Educación, Historia de la Educación y Pedagogía

Social. Campus Vida, s/n. 15782 Santiago de Compostela. ucia.dacunha@usc.es
\end{abstract}

Fecha de recepción: marzo de 2014

Fecha de aceptación: junio de 2014

Biblid [(1130-3743) 26, 2-2014, 163-182]

\section{RESUMEN}

El presente trabajo revisa el significado y la presencia social de la "cultura hip hop" en actividades educativas dirigidas a la población joven. Se pretende dar a conocer la evolución del hip hop, sus agentes, sus prácticas, su relación con el mundo de la industria musical y el de la acción sociocultural.

Se ofrece información de interés sobre el contenido de las letras de rap español, que han sido analizadas con el objetivo de contrastar las ideas que transmiten y sus referencias a los preceptos legitimados en la "cultura hip hop". Con ello se logra una pequeña aproximación al potencial del hip hop como medio de expresión de los valores que se identifican con la "cultura hip hop". Así, se conoce mejor el fundamento 
sobre el que se basan algunas experiencias educativas que han utilizado el hip hop para promover cambios en barrios, colectivos sociales o grupos de jóvenes.

Palabras clave: cultura hip hop; rap español; actividades educativas; jóvenes; construcción comunitaria; estrategias pedagógicas.

\section{SUMMARY}

This paper reviews the meaning of "hip hop culture" as a contemporary musical phenomenon, and how rap is a feature of the social and educational activities aimed at youth. The purpose of it is to show the evolution of hip hop, its agents, its practices, and its relationship with the world of the music industry and cultural action.

It provides useful information on the contents of the Spanish rap lyrics that have been analyzed to check the messages transmitted, the ideas and references to the precepts legitimized in "hip hop culture". This is an approach to the idea that hip hop is a means of expression of social concerns and values that identify the hip hop culture. So, this study aims to provide a better knowledge of some educational experiences that have used hip hop as a tool to promote change in neighbourhoods, social groups or youth groups.

Key words: hip hop culture; Spanish rap; socio-cultural activities; adolescence; community building; pedagogical strategies.

\section{SOMMAIRE}

Cet article révise l'importance de la présence sociale de la "culture hip-hop" dans les activités éducatives destinées aux jeunes. Le but est de présenter l'évolution du hip-hop, ses agents, ses pratiques, et ses relations avec le monde de l'industrie de la musique et de l'action socioculturelle.

Cette étude fournit des informations utiles sur le contenu des lyriques de rap espagnol, qui ont été analysés afin de comparer les valeurs transmises et les références aux dispositions de la hanche hip hop. Ceci est un peu plus prés le potentiel de hip-hop comme un moyen de d'expression des valeurs qui s'identifient à la culture hip hop. Donc, il est possible de mieux comprendre la base sur laquelle des expériences éducatives qui ont utilisé hip hop pour promouvoir des changements dans les quartiers, des groupes sociaux ou des groupes de jeunesse.

Mots clés: culture hip-hop; rap espagnol; socio-éducatif activités; jeunes; développement communautaire; stratégies d'enseignement. 


\section{BASES DE LA "CUlTURA HIP HOP»: BREVE HISTORIA, TEORÍA Y PRÁCTICA SOCIAL}

En una primera aproximación al significado de "cultura hip hop" es posible encontrar cierta variedad de referentes (Berti, 2009; Mithen, 2007; Reyes y El Chojin, 2010). Se le define como movimiento artístico, musical, popular o cultural; pero también como cultura, subcultura o filosofía, dado que el grupo de personas que están en relación con el hip hop tienen una particular manera de ver, pensar y hacer en sus vidas. Ha tenido una gran expansión por multitud de países y claramente se identifica el hip hop con ciertas expresiones artísticas orientadas a producir composiciones rimadas -el rap, que es interpretado por los maestros de ceremonia (MC), conocidos también como rappers-, con el estilo de baile breakdance, con el turntablism que mezcla los sonidos de varios discos de vinilo simultáneamente, o con dibujos y pinturas murales a modo de graffiti como particular forma de expresión plástica.

Estas características se diferencian de otras manifestaciones artísticas relacionadas con la música, la pintura o la danza generadas en otros movimientos culturales contemporáneos. De este modo, los grupos humanos vinculados al hip hop, en el transcurso de más de cuatro décadas, han podido reforzar sus señas de identidad al tiempo que integrar elementos novedosos surgidos en la dinámica de las ciudades como es el caso del skateboard o del beatbox. Esto es, elementos físico-lúdicos como el skate o musicales, como producir sonidos con la boca como caja de resonancia, se agregan al hip hop porque surgen en los mismos contextos y son dinamizados por las mismas personas. Constituyen, por así decir, un habitus (Bourdieru, 1997) en los miembros de la comunidad hip hop.

La comunidad científica se ha interesado en analizar algunos aspectos relacionados con el hip hop. La base de datos de Teseo del Ministerio de Educación recoge trabajos centrados en diferentes aspectos ${ }^{1}$ : comunicación, expresión artística, comportamientos de riesgo o estrategias comunitarias, pero con una preocupación común: dar a conocer los fundamentos y la repercusión social que está teniendo la "cultura hip hop" en el conjunto de la sociedad española, más particularmente en la juventud urbana.

1. La información básica sobre cada uno de ellos es la que sigue: 1) Graffiti, breakdance y rap: el hip hop en España (2003), de Francisco Jaime REYEs, como contribución al Departamento de Comunicación audiovisual y publicidad I de la Universidad Complutense de Madrid. 2) Graffiti hip bop femenino. La singularidad como significancia (2006), de Priscilla Danièlle GonçALves DE PAULA, del Departamento de Pintura de la Universidad Politécnica de Valencia. 3) Comportamientos de riesgo en adolescentes y jóvenes de la cultura bip hop. Un desafio a la atención enfermera (2009), de M. Ángeles García-CARPINTERo MuÑoz, del Departamento de Enfermería de la Universidad de Sevilla. 4) Práctica cultural comunitaria. El hip hop (2010), de Gabriela Inés BERTI, del Departamento de Filosofía de la Universidad Autónoma de Barcelona. Consultado en https://www.educacion.gob.es/teseo el 11 de julio de 2013 . 
En el campo de conocimiento de la Pedagogía social es conocida la existencia de iniciativas ligadas a proyectos socioeducativos que utilizan el rap como elemento motivador de la participación infantil y juvenil. De hecho, se pueden encontrar con facilidad a través de vídeos, redes y blogs multitud de experiencias en las programaciones educativas de colegios e institutos, en los festivales y encuentros organizados específicamente para jóvenes en centros culturales urbanos, etc. Al mismo tiempo, personas ligadas al hip hop realizan acciones divulgativas o reivindicativas. Todas ellas, son, pues, acciones que usan el hip hop como herramienta para la sensibilización ante determinados problemas sociales, para la mediación entre grupos antagónicos, para la ocupación del tiempo libre o para la reinserción de personas con dificultades de relación social.

El éxito de esta corriente musical y cultural ha tenido una gran expansión. Es más, ha dejado de ser un movimiento "underground" para convertirse en parte de la industria cultural de la música; lo cual hace que las personas vinculadas al hip hop, y en particular al rap, tengan intereses distantes y a veces contrapuestos. Tanto es así que un sector de rappers cree en la posibilidad de una transformación social a través de sus acciones y otro se limita a aprovechar el momento de las ganancias económicas que puedan generarse con las ventas de los productos ligados a la estética hip hop, que, sin negar su fuerte vinculación con las señas de identidad de esta comunidad -con su "cultura objetiva" (García Amilburu y García Gutiérrez, 2012)-, puede que sea uno de los elementos más influenciable por el efecto de las dinámicas del "estar de moda".

La "cultura hip hop" propone valores considerados positivos por la sociedad (colaboración, creatividad, comprensión, expresividad), sin embargo, la imagen que los medios de comunicación trasladan sobre el hip hop corresponde a un estereotipo negativo -y en cierto modo discriminatorio- de las comunidades de hiphopers. La información que los medios de comunicación ofrecen sobre el hip hop es, pues, parcial (Reyes y El Chojin, 2010), contribuyendo a divulgar los elementos relacionados más con la estética de la "cultura hip hop" que con otras de sus características identitarias (como, por ejemplo, la fraternidad, el afán de superación o la honestidad), que son muy valoradas por las personas que se reconocen como pertenecientes a la "cultura hip hop".

Se puede decir que, en general, la idea que la sociedad adulta tiene sobre el hip hop es negativa. Este hecho moldea, afecta y estigmatiza la construcción social de este movimiento y de las personas que lo siguen. Es por ello que, para fundamentar mejor el juicio de los profesionales de la educación -sean técnicos de educación y cultura, profesorado de primaria o secundaria, educadoras y educadores sociales, etc.-, es importante dar a conocer experiencias y proyectos sociales realizados a través de la "cultura hip hop". Entre otras muchas que han surgido y ocupado la programación educativa y cultural de centros cívicos y educativos, pueden mencionarse:

- Hip hop lab (ver http://www.hiphoplab.org) desarrolla propuestas dirigidas a población joven y a profesionales de la educación para que los 
elementos del hip hop les sirvan para abordar problemáticas como la marginación o la participación social.

- Vella escola (ver http://www.vellaescola.com/) es también una entidad que se dedica a organizar actividades dirigidas a la población joven: muchas directamente relacionadas con el hip hop como breakdance, graffiti, rap, beatbox, o turntablism (DJ), y otras relacionadas con prácticas físicodeportivas como skateboard, parkour, street basket, BMX, que se conocen como "cultura urbana" por su génesis y mayor desarrollo en la ciudades.

- La Campaña Rap contra el racismo de Movimiento por la intolerancia (ver http://www.rapcontraelracismo.es/) ha movilizado a jóvenes de todo el territorio español, y sus respectivos centros educativos, en la composición y difusión de líricas de rap a favor de la convivencia de todos los seres humanos sin discriminación de raza como derecho constitucional.

\subsection{Inicios del hip bop en España}

La "cultura hip hop" está presente en España desde los inicios de la década de los ochenta. Comenzó con la moda del breakdance y continuó con la del graffiti, para, ya a finales de los ochenta, dar el salto al rap. La presencia de los elementos clásicos del hip hop (rap, turntablism, graffiti y breakdance) en multitud de acciones socioeducativas vinculadas a la población joven (Carnacea y Cámbara, 2011) hace pensar en las potencialidades de la "cultura hip hop" que trascienden la mera expresión artística y las convierten en eje central de la intervención socioeducativa.

La representación social de la "cultura hip hop" identifica a ésta fundamentalmente con la música rap, acrónimo de Rithm And Poetry, y la moda de pantalones anchos y gorras dibujadas que se colocan la visera en todas las posiciones posibles. Pero, no debemos obviar también que la sociedad identifica el rap con la violencia y el sexismo. Recopilatorios como el realizado por Priya Parmar $(2010,93)$ con su alumnado estadounidense muestran que es común encontrarse definiciones de hip hop como misógino -identificado en expresiones como que "trata a las mujeres como meros objetos sexuales refiriéndose a ellas como "putas" y "culos" ", violento -verbalizado como que "le van los gansters y los jóvenes que actúan a lo salvaje»-, sexista, homófobo, materialista -dado que enuncian su parecer con frases como "les importa más la riqueza material mostrando el "bling bling" del dinero, los coches, la ropa, las joyas, las mujeres y las mansiones»-, además de ver el hip hop como un gueto musical o un montón de jerga ${ }^{2}$. Las comunidades educativas

2. El hecho mismo de que la comunidad hip hop tenga una jerga es síntoma de su interés por utilizar el lenguaje como medio de afirmación de su identidad social. Es así -con la adopción de un argot particular- como las comunidades culturales tratan de diferenciarse de otras por el código lingüístico que utilizan para expresarse (Mithen, 2007, 38), en este caso, a través de la música rap. 
donde se quiera utilizar el hip hop como elemento motivador de la participación pueden oponer cierta resistencia, por esta asociación con contextos transgresores, vulgares o extraños.

La influencia que ejercen los movimientos sociales, culturales y musicales de Estados Unidos en muchos países del mundo es bien conocida. En el caso de la "cultura hip hop", que se inicia en los años setenta en algunos barrios de Nueva York como el Bronx, llega a España en los años ochenta de la mano de los soldados americanos asentados en ciertas bases militares ${ }^{3}$, algunas películas de cine, programas de televisión y también a través de los turistas estadounidenses que venían a España y traían con ellos información sobre el hip hop (Chang, 2000; Reyes y El Chojin, 2010; Fraga, 2000; Berti, 2009). Una nueva estética en la forma de vestir y un ritmo musical diferente, el rap, cautivó a muchas personas que quisieron conocer, imitar y autorrealizarse a través de estas innovadoras costumbres: "La juventud de Torrejón quería ser como los americanos de la base, quería llevar sus zapatillas, sus vaqueros, escuchar su música" (Elola, 2008). Se puede decir que se trataba de un movimiento cultural en cuanto a que se estaba produciendo un cambio en las formas estéticas, artísticas y filosóficas de un grupo de personas que se convertirían en modelos para otras muchas. El modo de expresar el pensamiento juvenil, su percepción de la situación social de su grupo de referencia y de los conflictos entre grupos de jóvenes tuvieron la capacidad de impactar, eso sí, encandilando a bastantes personas y provocando el rechazo en otras muchas. Uno de los elementos llamativos de los movimientos sociales asociados a nuevos ritmos procedentes de otros países, sobre todo anglófonos, es el hecho de que, a pesar de no comprender la lengua en la que se están expresando tienen un éxito masivo. La innovación que suponen frente a la cultura musical preexistente ocupa lo que Groys (2005) llama espacio profano, en tanto que no forma parte de la memoria cultural custodiada por instituciones jerarquizadas, como puedan ser los archivos, los museos, las bibliotecas. Cuando lo novedoso irrumpe en la escena provoca emociones ambivalentes y contradictorias, pero al tratarse de ritmos musicales "arrastran" a las personas a moverse -tamborilear con los dedos, por ejemplo- por ser ésta una característica de la música como lenguaje no referencial (Mithen, 2007).

\subsection{Un apunte sobre el breakdance}

Iniciada la década de los ochenta, momento en el que se inscribe la difusión del hip hop en España, se hace visible el breakdance en la península. Al contrario de lo que muchas personas piensan, bailar break requiere mucha dedicación y disciplina

3. Singularmente contribuyó a la difusión de la cultura hip hop la base de Torrejón de Ardoz (Elola, 2008), pero el fenómeno también tuvo lugar en Zaragoza, Cádiz y Sevilla, extendiéndose rápidamente por las grandes ciudades españolas a finales de los ochenta. 
para ejecutarlo, porque es una combinación de ejercicios aeróbicos, gimnásticos y de expresión corporal muy complejos y difíciles de realizar. Una vez más, las novedades rítmicas procedentes de Estados Unidos hacen mella en los gustos europeos y muy particularmente en los de la juventud urbana ${ }^{4}$.

La emisión de ciertos programas de televisión tuvo mucha influencia en la expansión de la moda break que fue invadiendo los barrios, colegios y plazas públicas. Son ejemplos que se citan sobre lo acontecido en esta época, entre otros:

Las actuaciones de Break Machine en programas musicales emitidos por televisión, la aparición del break en un programa infantil de la época denominado Dabadabadá, la popularidad de la serie Fama dirigida a un público joven y con la temática de las escuelas de baile como fondo, así como otros elementos presentes en los medios de comunicación (concursos como Tocata) y su presencia en publicidad, como en los anuncios de las bicicletas BH o las carteras Perona (Reyes y El Chojin, 2010, 59).

El hecho de que el breakdance se practique directamente sobre el suelo, con apenas un cartón, y que la música sea posible reproducirla en un aparato portátil o simplemente realizarla en directo a través del beatbox, hizo más fácil su popularización. Además, la indumentaria tipo "chándal" -que ahora vemos como normalizada, pero que en aquella época fue rompedora con respecto a las normas de lo que deben vestir las personas para estar en la calle-, conectó fuertemente con el público juvenil urbano (Reyes y El Chojin, 2010) siempre deseoso de diferenciarse de la sociedad adulta y de probar cosas nuevas procedentes de contextos ajenos. Lo nuevo puede ser valorado como una exigencia cuando los valores antiguos están convenientemente archivados y no corren el peligro de ser destruidos por las innovaciones o por el paso del tiempo (Groys, 2005, 31). Para la juventud ser original es en cierto modo una de sus atribuciones más queridas, aunque en la práctica suponga un comportamiento gregario propio de la cultura de masas.

En cierto modo, esta nueva dinámica urbana dio como resultado la aparición de grupos breakers en las grandes ciudades españolas y en otras muchas medianas, de las que en Galicia es ejemplo Vigo, tal y como atestigua Gabriela Berti5:

4. Según Reyes y El Chojin $(2010,45)$ cuando se estrenaron películas como Beat Streat y otras del estilo (Breakdance, de Joel Silber, 1984; Electric Boogaloo, de Sam Fistember, 1984; o Body Rock, de Marcelo Epstein, 1984) se hizo muy popular el breakdance y en muy poco tiempo muchas personas se apuntaron a la nueva moda.

5. Gabriela BERTI es una investigadora de la cultura hip hop en su Argentina natal y en países europeos como España, Italia, Alemania y Francia. En 2009 ha publicado el texto Pioneros del Graffiti en España (Universidad Politécnica de Valencia) en el que se documenta y se describen entrevistas a personas relevantes del hip hop hispano. 
Alicante, Barcelona, Girona, Lleida, Madrid, Palma de Mallorca, Sevilla, Córdoba, Valencia, Zaragoza... eran un testimonio de este florecimiento imparable. Se solían encontrar los breakers de diferentes barrios una vez a la semana en algún punto de sus metrópolis, para intercambiar conocimientos, información y/o comprobar las fuerzas de la crew. Plaza Universitat en Barcelona, Nuevos Ministerios en Madrid, Plaza de España en Sevilla, Viveros en Valencia, son solo una muestra del fenómeno (Berti, 2009, 67).

La vistosidad del breakdance se complementa con la expresión plástica del graffiti y, al igual que los otros elementos del hip hop, concita pasiones e intensos rechazos sociales.

\subsection{Breve aproximación al graffiti}

La aparición del graffiti en España a inicios de los ochenta es coincidente con los motivos mediáticos ya señalados antes para el breakdance. El registro de pintadas con spray, según el objeto y propósito de las mismas, puede ser anterior, pero, si nos circunscribimos a la identidad de la "cultura hip hop", la convención es que el pionero en Madrid fue El Muelle (Reyes y El Chojin, 2010, 60), en cuyo "tag", o firma, aparece una flecha subrayando la palabra "muelle". Las personas que "firman" en las paredes, vagones o muros se denominan "writers" y se suman a un nuevo estilo plástico, un nuevo código de imágenes y simbolismos ligados a culturas urbanas. También las portadas de los discos servían a los grafiteros españoles para dar a conocer la evolución de este nuevo estilo, dado que en las carátulas de algunos discos se reproducían fotografías de graffiti. Así, la circulación comercial o "de mano en mano" de estos discos servía de modelo a muchos "writers" que se iniciaban haciendo sus primeras "piezas sobre las paredes" (Fraga, 2000). El graffiti, es la expresión plástica del arte hip hop y al igual que otros de sus elementos genera controversia, en este caso, porque utiliza el espacio público y el privado como lienzo de libre disposición. El tipo de materiales que se utilizan tienen una larga duración, son tóxicos y, además, los elementos comunicativos (mensajes, códigos, reivindicaciones) no son compartidos por una amplia mayoría de la ciudadanía, sino que se restringen a los hiphopers o a quienes se revelan contra ciertos elementos del statu quo.

Respecto al graffiti, la mayor influencia vino -como sucedió con los cuatro elementos del hip hop- de las películas norteamericanas que registraban la efervescencia del hip hop en Estados Unidos (Berti, 2009, 59). De este modo, se fueron introduciendo en España no sólo las imágenes, sino también la cultura de los artistas del graffiti con todo su lenguaje, sus costumbres, sus tendencias en ropa y complementos, así como el espíritu de competencia que inunda el hip hop. Este espíritu de competencia, y la "chulería" que se muestra en muchas ocasiones, para decir que uno es el mejor en determinado ámbito, está directamente ligado a la superación personal; esto es así porque cuando una persona pretende ser la mejor 
en algo debe superar a sus rivales, y cuanto mayor sea el nivel de estos, más se ha de trabajar para lograr vencerles, evitando así la derrota. Este espíritu de competición que existe dentro del hip hop, que hace parecer engreídas a muchas personas, no es más que un reto personal del tipo "si tú puedes, yo puedo". Por lo tanto, esta actitud desafiante que en ocasiones se asocia con la "cultura hip hop" es, en cierto modo, un motor para que las personas evolucionen y mejoren.

Es preciso tratar de entender lo que significaba para aquellos jóvenes realizar graffitis. Era su modo de expresarse, sentían que pertenecían a un colectivo minoritario, diferente e incomprendido. Todo ello dio como resultado, una vez que pasó el bum de la moda, que integrantes del hip hop se identificasen como luchadores/as y defensores/as de la cultura hip hop y sus elementos (Chang, 2000; Reyes y El Chojin 2010; Fraga, 2000).

\subsection{El rap en la "cultura bip bop"}

Es posible que muchas experiencias con nuevos ritmos sean éxitos efímeros, por lo que las personas que lo vivieron en primera persona no tenían certeza alguna de si aquello sería duradero o no. A mediados de los ochenta en España se vivió un período de innovaciones, no sólo en el campo musical identificado con la Movida Madrileña y la "movida" en otras urbes, sino que se estaban experimentando cambios en la política, con una reconstrucción de la democracia después de un largo período de dictadura, y también en la consideración social de la mujer, que veía ampliadas sus posibilidades de ser ciudadana de pleno derecho.

La poesía dialogada es una práctica popular antigua que se mantiene en sus diferentes variantes culturales. Las diferentes formas existentes en España, América latina y otros lugares de cantar improvisando rimas, o de abordar un tema entre dos personas que compiten rimando sus argumentos, son cantares populares ${ }^{6}$. Por ejemplo en Galicia existe la tradición de la regueifa, en el País Vasco los bertsolari, en Menorca el glosat, en Granada y Almería el trovo, etc. Por lo que al rap se refiere, su origen está en la cultura negra norteamericana que transforma el ritmo de blues en el talking blues para contar historias de una manera más o menos recitada.

Una de las finalidades de la música es suscitar emociones en las personas que la escuchan, a través de las circunstancias, pensamientos o ideas que se narran. La música entretiene, ambienta, comunica, conciencia, y lo que es más importante: "Se cuenta entre las necesidades espirituales más primigenias del ser humano; ni siquiera en nuestro mundo tecnificado se ha atrofiado esta necesidad de música" (Michels, 1982).

6. Existe una página web que informa sobre la improvisación oral en el mundo: http://www. argodat.com disponible en idioma euskera. Consultado el 11 de julio de 2013. 
Hasta finales de los años ochenta en España no se introdujo el rap como tal, de hecho el término utilizado para referirse a este ritmo era música de break, porque se asociaba a la moda del break en España.

A partir de 1989 empiezan a editarse los primeros temas de rap en español, hecho por b-boys y/o b-girls españolas, dos sellos discográficos (Troya y BMG-Ariola) apostaron por la nueva música en español. La época que transcurrió entre 1989-1991 será considerada como el boom del rap en España... En 1989 empezó el boom del rap en nuestro país (el segundo intento de asentamiento de la cultura hip hop desde que entrase en 1984 en forma de breakdance). En este año, casi todas las novedades de rap estadounidense se podían adquirir en cualquier tienda de música, y lo más importante: gracias a la iniciativa del fotógrafo Miguel Trillo, se edita el primer disco de rap en castellano: Madrid Hip Hop (Reyes y El Chojin, 2010, 77).

Que se editase el primer disco de rap en español significaba que había movimiento y una red de profesionales de sonido en torno al rap. El estilo del rap español se decantó por la maqueta -que no es más que una grabación de escasa calidad y con pocos medios- por el rechazo de las personas integrantes de la "cultura hip hop" hacia la industria musical (Reyes y El Chojin, 2010; Fraga, 2000). En este sentido, los valores que el hip hop representa (cooperar, compartir, ser honesto) no son coincidentes con los intereses de la industria de la música.

Para poder apoyar de forma cuantitativa el seguimiento que tiene la "cultura hip hop" en España, se ha buscado información sobre el consumo de música rap. Parte de los datos que se ofrecen se han comparado con información sobre otros estilos musicales, logrando de ese modo una representación aproximada del lugar que ocupa el rap dentro de la escena musical española. Estos datos aportan una imagen cuantificada del rap en España. Así, desde el recopilatorio realizado por Jesús Miguel Marcos (2009), sobre los discos más vendidos de la historia del rap español (Figura 1), se puede visualizar una serie cronológica de cifras de ventas.

FiguRA 1. VENTA DE DISCOS DE HIP HOP ESPAÑOL 1994-2008

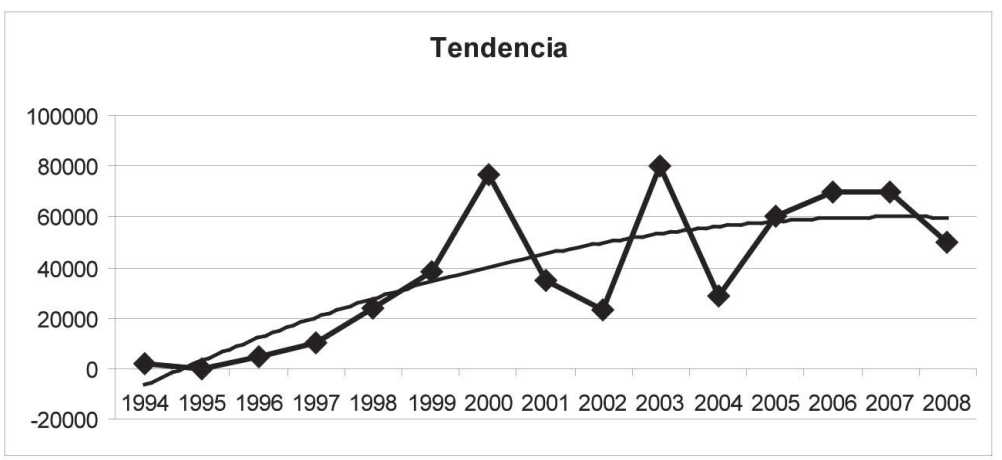

FUENTE: Elaboración propia a partir del recopilatorio de MARCos (2009). 
Como se observa en el gráfico anterior, el consumo de música rap ha ido en aumento desde la década de los noventa. La línea de tendencia polinominal así lo atestigua con un crecimiento constante durante una década y un estancamiento en los últimos años de esta serie, probablemente motivado por la crisis económica y las alteraciones en todas las esferas de consumo que ha provocado. No obstante, estas cifras por sí solas no avalan una cultura. No todas las personas que compran música rap tienen el mismo compromiso con el hip hop, del mismo modo que no todos los artistas asociados a esta etiqueta industrial tienen interiorizado el mismo sentido de responsabilidad para con la transformación social que se pretende desde la "cultura hip hop".

Como es sabido, existe un descenso continuado en el mercado musical físico, así como un aumento constante, en los últimos años, del consumo de música por Internet (Promusicae, 2014). Es por ello que utilizar datos de consumo de música rap por Internet ofrece una información complementaria sobre la presencia de la "cultura hip hop" entre las personas consumidoras de música virtual, mayormente jóvenes. Está abierta la discusión sobre si la población joven está protagonizando una brecha generacional por la forma en que satisfacen sus necesidades de información. La denominación de "generación google" ya identifica en las personas más jóvenes un manejo diferente de la información digital (Hernández, Jomes y González, 2011), pero las personas adultas activas en el uso de la informática no representarían una diferencia sustantiva. Donde sí puede haber disparidad es en el consumo de productos culturales porque es en este ámbito donde la juventud "despliega su visibilidad como actor social" (Morduchowicz, 2008, 47).

La web hhgroups.com -principal referencia, a nivel español, de subidas y descargas de rap en la red- ${ }^{7}$ tiene en archivos on line maquetas de artistas hip hop, amateur y profesionales, que logran más de 206 millones de descargas en el período consultado (desde el 08/10/2005 hasta el 2/08/2012). Estas cifras representan parte de la presencia del hip hop en el ocio de la juventud, tanto como creación, expresión artística, como de consumo de música rap. Al calcular la media de descargas diarias de maquetas o discos en Hhgroups, en sus siete años de funcionamiento, el resultado es, aproximadamente, cincuenta mil descargas diarias. Para el mismo plazo de tiempo, la media de trabajos musicales que se han subido al día a Hhgroups es de tres.

El significado de los datos de descarga on line de música rap en España se entiende mejor si se considera el hecho de que la industria musical física española está en constante decrecimiento y, por el contrario, el consumo a través de Internet

7. Los datos que ofrece su página son los siguientes: Usuarios: 165302, Suscritos: 112292, Fichas: 42353, Letras: 4122, Entrevistas: 80, Graffitis: 6930, Foros: 203294, Videos: 4724, Temas: 22934 Bases: 16267, Maquetas: 7849, Coment.: 595621, Noticias: 2330. http://www.hhgroups.com/cultura-hiphop/ (Obtenido el 2.08.2012). 
aumenta. Esto conlleva que en este momento las descargas on line son un medio de información sobre el consumo de música.

Por otro lado, la Asociación de Música en Internet, como organización sin ánimo de lucro que sirve de plataforma de apoyo para artistas -destacando su compromiso con el copyleft y con el desarrollo de proyectos de investigación musical-, realizó, en el año 2006, un informe sobre la web myspace.com, en el cual se pone de manifiesto que existen más de cuatrocientos mil grupos o personas en solitario que producen música hip hop, y aproximadamente trescientos mil que crean música rap ${ }^{8}$. Sumando las cifras exactas de los dos grupos representantes de la "cultura hip hop" serían 733.978 perfiles. Estas cifras se pueden comparar con las del rock (427.342), las del pop (127.339), las del indie (180.759) o las del techno (54.792) (Asociación de Música en Internet, 2006), como ejemplos que destacan en volumen de entre un total de 44 estilos musicales diferentes. El total de perfiles de myspace.com, en el año 2006, asciende a 4.233.536, cifra de la cual la música relacionada con la "cultura hip hop" representa el 17,38\% que, dada la diversidad de estilos musicales, pone en evidencia la importante producción de hip hop.

\section{EDUCABILIDAD E IDEALES PRESENTES EN LAS LETRAS DE RAP}

Existen prácticas socioeducativas que se realizan a través del hip hop en diferentes asociaciones dentro del contexto español. Como ya hemos dicho, son ejemplos de ello, entre otras muchas, Hip Hop Lab (Barcelona), Vella Escola (Galicia) y Rapeadero de Lavapiés (Madrid). Además, las programaciones culturales dirigidas a la población joven de multitud de ayuntamientos tienen en su oferta música, talleres y exhibiciones relacionadas con las prácticas, estilos y manifestaciones de la "cultura hip hop".

El hip hop contiene elementos atractivos para la juventud. Un estudio representativo de la población española de entre 12 y 16 años muestra que un 1,8\% de las personas encuestadas $(\mathrm{N}=3.306)$ tiene como hobby principal el hip hop (indicado en la encuesta directamente o sugerido a través de alguna de sus prácticas como Breakdance, Skateboard o Graffiti) y para un 5,3\% lo es escuchar música. En un estudio (Caride, 2012) realizado sobre los "Tiempos escolares y tiempos de ocio: problemáticas específicas y alternativas pedagógico-sociales en la vida cotidiana del alumnado de Educación Secundaria Obligatoria " ${ }^{9}$, se pone de manifiesto que los intereses de la juventud son muy variados: los estudios, las amistades, el

8. El hip hop engloba otros estilos musicales diferentes del rap, como es el turntablism o el dancehall, por eso es frecuente encontrar listados musicales que diferencian rap de hip hop. Para más información ver www.asociaonmusica.es/interes/informes. Consultado el 11 de julio de 2013.

9. Proyecto (Psi2008-04308/PSIC) financiado por el Ministerio de Ciencia e Innovación, con fondos FEDER, en el marco de la convocatoria pública del Plan Nacional de I+D+i correspondiente al período 2008-2011. 
deporte, la música, los juegos de ordenador o juegos en todo tipo de versiones electrónicas, el descanso, etc. Como lo que identifican con "un día divertido" es salir con las amistades (Morduchowicz, 2008), más que mirar televisión, el hip hop les ofrece motivos para estar fuera, fundamento para hacer cosas y retos de aprendizaje para mejorar habilidades físicas, plásticas y comunicativas.

El perfeccionamiento que cada persona hace como modo de interiorizar la cultura de la cual quiere formar parte, de asimilación vital de la cultura en la que vive se asienta en el principio de educabilidad (García Amiliburu y Garcia Gutiérrez, 2012, 37). Así, los miembros de "cultura hip hop" comparten conocimientos, destrezas, costumbres, etc., potenciando el refuerzo de la cultura subjetiva.

Es por ello que, desde los planteamientos de la pedagogía crítica -aquella que pretende crear las condiciones educativas necesarias para contribuir a la transformación social (Freire, 2003; Aubert y otros, 2004; Freire, 2009)-, los profesionales de la educación social y de la educación escolar deben replantearse su relación con las personas y con las comunidades de las que son parte. Esto es, el trabajo educativo debe liberarse de los prejuicios existentes para con el hip hop y, por tanto, ser exigente con una cultura pedagógica que anime a explorar, descubrir, reconocer y respetar la riqueza cultural. Sólo así será posible reconocer que la "cultura hip hop" está íntimamente ligada a la identidad social y cultural de los jóvenes escolarizados (Pramar, 2010, 87).

Se pronuncia muy frecuentemente que el interés de la educación es la formación de una ciudadanía crítica ante las injusticias sociales, respetuosa con las diversidades y autónoma en la satisfacción de sus necesidades y aspiraciones culturales. Pues bien, una forma de aproximarse a una persona o a un colectivo es a través de sus inquietudes y motivaciones o utilizando estrategias que permitan la libre expresión de las mismas. La "cultura hip hop" anima a la solidaridad, la cooperación y a la crítica de las injusticias sociales. Tanto es así que en determinados contextos se ha transformado en herramienta socioeducativa, generando motivación en el sector más joven de la población, que en su etapa vital adolescente busca definir los valores con los que querrá autodefinirse individual y grupalmente. El lenguaje artístico del hip hop, empleado como recurso pedagógico, permite educar en el rechazo ante las injusticias que afectan a las personas que identificamos como próximas o lejanas, así como para declarar la adhesión a determinados principios éticos ${ }^{10}$.

10. Ejemplo de ello es la Declaración de Paz del Hip hop (Arte hip hop, 2012), un documento que fue entregado por las personas integrantes de El Templo del hip hop en la sede de Naciones Unidas el 16 de mayo de 2001. Esta declaración proporciona un marco para la existencia y desarrollo de una comunidad internacional hip hop. Las personas que suscriben esta declaración tratan de reconfigurar la estereotipada imagen pública del hip hop, mostrando otras facetas de la cultura hip hop a través de los trabajos de hiphopers como KRS-One, Dj Kool Herc, Áfrika Bambaataa, Grand Master Flash, Jeru the Damaja o Gang Starr. Ver http://lenwadura.blogspot.com.es/2009/01/la-declaracion-de-paz-creada-x-el. html (consultado el 28 de diciembre de 2013). 
El "Santuario" que representan los centros educativos no da la bienvenida al rap (Parmar, 2010, 88), pero la formación de formadores en la aplicación de una pedagogía crítica a través de las líricas del rap permitiría reconocer, comprender, validar, incluir las experiencias, el conocimiento, la cultura y subculturas de las y los estudiantes colocándose así como principal línea de acción de una pedagogía cultural.

\subsection{Contenido actitudinal transmitido a través de las letras de rap}

Para poner de manifiesto algunas de las temáticas que se abordan en el hip hop, puede ser adecuado un análisis de contenido de letras de rap, aplicando una categorización ad hoc procedente de la revisión de los preceptos de la "cultura hip hop", con el fin de resaltar y analizar algunos de los elementos más presentes en los mensajes, ideas y actitudes con los que la "cultura hip hop" se identifica. Del conjunto de preceptos del hip hop se han identificado una serie de palabras clave, que pueden funcionar como categorías para el análisis del contenido de las letras de rap.

En este trabajo el centro es el rap, ya que se pueden conocer los valores y actitudes que éste transmite por la particular forma de expresar las ideas de la "cultura hip hop" mediante textos en verso. Las letras de rap serán, pues, la base del análisis, en el que se intentará prescindir de aspectos ligados a la forma, el ritmo, la rima, etc., para presentar el mensaje y la historia que se quiere contar en esta modalidad de recitación rítmica. Los contenidos de las letras de rap transmiten ideales, actitudes y emociones. Así, de su análisis se podrán inferir una parte de los significados que los rappers otorgan a esta manera de vivir y construir el mundo.

A continuación (Figura 2), se presentan en orden alfabético dieciocho palabras clave obtenidas del desglose de los dieciocho respectivos preceptos de la carta mencionada:

FiguRA 2. LISTADO DE VALORES PROMOVIDOS POR LA “CULTURA HIP HOP»

\begin{tabular}{|c|c|c|}
\hline ANTEPASADOS & EDUCACIÓN & LEYES \\
\hline Asociación & Especialistas & Madre Tierra \\
\hline Celebración & Inclusión & Mercado \\
\hline Comunidad & Honestidad & Paz \\
\hline Cooperación & Identidad & Solidaridad \\
\hline Cuidados & Influencia & Vida \\
\hline
\end{tabular}

FuENTE: Elaboración propia a partir de la Declaración de paz del hip hop (ARTE HIP HOP, 2012).

Consideramos que la creación de composiciones líricas, su reproducción y escucha, así como la presencia de elementos de competición propios de los b-boys 
y b-girls, forman parte de una construcción comunitaria de los grupos que se identifican como parte de la "cultura hip hop" y de aquellos que observan desde la distancia. Tal y como expresan los que defienden la educación dialógica (Gómez et al., 2006: 45) "a través del diálogo, todas las personas se constituyen en agentes transformadores de sus contextos". Así, las ideas que se vehiculan a través de las letras de rap son relevantes porque forman parte de la interlocución entre las personas que están escuchando, rapeando u observando este movimiento urbano.

Para sistematizar el proceso de selección se hizo una consulta informal a personas ligadas al hip hop sobre sus temas de rap preferidos, de modo que colaborasen en la confección de una lista de canciones que pudiesen transmitir las preocupaciones sociales presentes en las composiciones líricas del rap ${ }^{11}$. A través del análisis realizado a las letras de rap, se ha visto que las categorías más utilizadas son: la "solidaridad", que se ha encontrado en una representación del 66\% del total; la "paz" y la "educación", presentes en más de la mitad de los temas utilizados en este estudio; la "influencia" y la "comunidad" también están presentes en la mitad de los temas empleados; y, por último, la "honestidad" y las "leyes" se repetían en una proporción del 40\%.

- Cuando dentro del hip hop se hace referencia a la "identidad", ésta se debe entender como la conciencia colectiva, marcada por experiencias callejeras, y transmitida en la actitud expresada a través de los elementos culturales. De este modo, las personas que se identifican con la "cultura hip hop" se diferencian de la mayoría que no lo son. Así Líriko lo expresa en el tema No somos ciegos: "mejor ser un extraño, que no uno más del rebaño". Ser parte del hip hop significa apartarse en cierto modo de otras tendencias. Pero, además, las claves identitarias que fornece la "cultura hip hop" permiten alegatos a favor de la paz social entre grupos que rivalizan. Dentro del tema Unidos por el flow se encuentra este verso: "No hay horizonte ni fronteras que nos separen, no hay diferencias de creencias ni de mensajes, unidos por el mismo sueño en una canción, amor de reina para la gente de corazón”. Este texto está escrito por una reina de los Latin King $^{12}$, a través de él reclama que se acaben las disputas violentas con

11. La lista de temas analizados es la siguiente: Título, autora/or y año: Cadenas, Nach (2005); Información planta calle, Violadores del Verso (parte Kase.O) (2006); No somos ciegos, Violadores del Verso (2006); Manifiesto, Nach (2008); Rap contra el racismo, El Chojin (2011); Deteneos, Dnoe (2007); Zona minada, Arma X (2009); Trabajadores, Los chikos del maíz (2007). Nefasto contexto, Bkc (2003); Devoto, Tote (2004); Unidos por el Flow (2008); Aprendeo, Aid (2011).

12. Los Latin King son una organización de procedencia latinoamericana (fundamentalmente México y Centroamérica) con actividad en España. Su imagen más conocida los relaciona con actividades delictivas como el narcotráfico. Es por ello que esta experiencia de Unidos por el Flow dio una imagen y una experiencia vital diferente a los miembros de esta banda y a su rival los Netas. 
los Netas ${ }^{13}$, ya que considera que todas las personas de la comunidad hip hop son iguales. La "educación" en el hip hop es una parte fundamental en muchos aspectos, pero principalmente se hace referencia al hecho de poder definirse. Dentro de esta posibilidad de definirse, una autoestima sana es importante, ya que da seguridad a la persona, y precisamente con el objeto de reforzar la autoestima se pueden elaborar estrategias pedagógicas que utilicen los elementos culturales del hip hop.

- El proporcionar "cuidado" es muy importante para el hip hop, esto es, ayudar y cuidar a las personas que te rodean. Esta cultura considera que la única forma de lograr respeto para el hip hop es que los hiphoppers se cuiden entre sí. Los chikos del maíz en su tema Trabajadores dicen lo siguiente: "Dedicado a la clase trabajadora, dedicado a las madres con jornadas de veinte horas", de este modo ponen de manifiesto la reclamación ante agencias e instituciones para que observen con otra mirada la opresión en la que viven buena parte de las mujeres madres y las personas con trabajos por cuenta ajena en régimen de explotación.

- La categoría "comunidad" hace referencia a un grupo unido por elementos en común, entre estos destaca una lengua propia, como pasa dentro del hip hop con el Hip Hop National Language (HHNL). En el contexto español, desde el hip hop se hace reivindicación de las lenguas propias de las comunidades de las que forman parte (gallego, catalán y vasco son idiomas del rap que se produce actualmente). De hecho la conocida rapera gallega Aid en su tema Aprendeo así nos lo recuerda: "Podo ser a túa voz, podo ser o teu medio de comunicación, eu podo ser ti, ti podes ser eu, un pobo cunha cultura ten unha voz de seu".

- "Solidaridad" es la categoría que más veces se repite entre los doce temas utilizados para el análisis. Este valor, dentro del hip hop, y más concretamente en el rap, está muy relacionado con el empleo de la palabra en la lucha contra la injusticia. En los preceptos del hip hop se expone que la cultura, a través de las personas que componen este movimiento social, se debe implicar en la búsqueda de soluciones ante las desigualdades que se encuentre. Nach en el tema Cadenas dice: "Todo el fuego que escupas, provocará un mal, que volverá a ti como un boomerang", a través de esta frase su autor resume la idea expresada a lo largo de la letra, que todos estamos conectados, y que es necesario que nos respetemos y seamos solidarios los unos con los otros, por el bien de toda la comunidad.

- Dentro del hip hop la "honestidad" es un aspecto muy importante, ya que la comunidad exige -a las personas que se quieran sentir dentro de esta

13. Los Netas son una organización que ha sido acusada de robo y tráfico de drogas en los países donde tiene presencia (EE. Uu., América Latina y España, entre otros). Su rivalidad para con los Latin Kings es frecuentemente uno de los motivos de publicidad de sus acciones violentas. 
cultura- que sean honradas, dignas y justas en todos los aspectos de la vida. La actitud de respeto, que se pretende mostrar desde la "cultura hip hop", está estrechamente vinculada con este valor comunitario de la honradez, ya que la honestidad en los negocios y en las relaciones humanas se basa principalmente en ser respetuoso y justo. "Van a usar publicidad para engañarte, triste arte he visto muchos tontos en el Media Market", con este verso de la parte de Kase.O del tema Información planta calle se pone de relieve la importancia de la honestidad o se critica su ausencia. También en la letra de Bkc, del tema Nefasto contexto, se pone de relieve la exigencia de honestidad, que existe dentro del hip hop, a través de frases como esta: "Ladrones de guante blanco, correctos empresarios, que se embolsan legalmente todo mi esfuerzo diario". Para el hip hop, el cumplimiento de las "leyes" es muy importante, ya que a través del respeto a las mismas se logran experiencias positivas entre los hiphoppers, y favorece las relaciones de la comunidad hip hop con instituciones ajenas al movimiento. Este respeto a las leyes se ve reflejado en el tema Devoto de Tote con la siguiente frase: "A quién estafas cofrade? El Estado es aconfesional, tu opción ilegal, nadie lo sabe?».

- Los artistas hip hop deben ser conscientes de la "influencia" que ejercen en la sociedad, principalmente en la juventud, y así se le reclama desde los preceptos culturales de la Declaración de la Paz. Es por ello que las personas ligadas al hip hop han de tener siempre en cuenta este hecho antes de exponer una opinión públicamente. Un ejemplo de esta idea está presente de forma transversal a lo largo de todo el tema Rap contra el racismo, proyecto iniciado por El Chojin, en el que colaboran varios artistas de la escena rap española.

- El hip hop rechaza la violencia, y contempla la revolución como última vía para el desarrollo hacia la "paz". Cuando se hace referencia a esta categoría, se debe tener en cuenta que en los preceptos de la "cultura hip hop" se entiende la paz como un objetivo, ya que se considera que el mundo en la actualidad no convive pacíficamente. En el tema de Dnoe Deteneos, se refleja el rechazo que existe hacia la violencia de género, dentro de la "cultura hip hop". En esta frase: "deteneos chicos, defendeos chicas" la autora exige a los chicos que detengan esta injusticia y a las chicas que se defiendan de ella, ya que si se desea cambiar algo hay que participar activamente en la dinámica del cambio.

Las actitudes que se transmiten, en la actualidad, en las letras de rap españolas responden a la construcción de los valores por los que el hip hop luchaba en sus orígenes: revertir las condiciones de opresión de las personas socialmente marginadas por su pobreza, religión, raza u origen social. Denuncian el fraude, la desigualdad, la violencia de género, la explotación (proletaria), la "trata" de personas, el racismo. Admiran la resistencia activa, el talento, "reventar" cosas, la implicación del grupo y de las personas. Desprecian la adoración del dinero, lo comercial y la 
hipocresía. Las categorías más representadas, en las letras analizadas, contienen en sí mismas la esencia de las propuestas educativas para las comunidades sobre las que pretendía influir: solidaridad entre las personas del barrio, rechazo a las posturas violentas y derecho a educarse o autodefinirse como una comunidad diferente del contexto consumista acrítico que los rodea.

Final rap

Vestirse comparando ni lo comprendo ni lo comparto el camino más rápido a venderse comprando es, de ratas un mundo de marcas, ir en bus perder status, señoras y señores dónde están sus valores en bolsa en dólares, con lo que me dan pago por comer olores, te pegue Van Damme un patadón en los, dan circo y pan como siempre se hizo y no hay pan pan para tanto chorizo.

Compran tu tiempo con trabajo, te esclavizan por un sueldo relativamente bajo, les importa un carajo el sudor de tu frente, solo piensan en volverte a quitar el verde y joderte.

Esta sociedad sin rebeldes sexualiza y privatiza, una herida abierta, Franco murió nadie echó al minúsculo, eso no cicatriza.

Ser valiente no es inteligente gente dice, ser cobarde es rentable, más que un sable en el vientre, así lo comentan, pero yo no hablo de eso, hablo de compartir paraguas en la tormenta y así si, salir todos ilesos que fácil sería que los que pudieran quisieran verlo qué vida es esa que te pasas currando? por cuatro pesos y falsas promesas de ascensos, lavan tu seso con sexo, hacen que el convexo sueñe el cónvavo de la del sexto, movimiento de plexo bajo luz de flexo, que quema, igual que yo, representando la escena en el texto.

Hip hop sirve para todo esto colabora con nosotros a través de tu contexto. Hip hop vino para dar talla en la calle con la peña vaya donde vaya.

Hip hop sirve para todo esto colabora con los otros a tarvés de tu contexto. Hip hop vino para dar tralla en la calle con la peña coño vaya donde vaya, de la primavera al otoño, de la montaña a la playa.

(Autoría: NotamC) 


\section{REFERENCIAS BIBLIOGRÁFICAS}

ANKI TONER (1998) Hip-hop. Madrid, Celeste.

ARTE HIP HOP (2012) Declaración de paz del hip hop. Consultado el 18 de diciembre de 2013.

http://artehiphop.com/declaracion-de-paz/.

ASOCIACIÓN DE MÚSICA EN INTERNET (2006) Informe: Difusión de música por Internet. Consultado el 18 de abril de 2012.

http://www.asociacionmusica.com/docinformes/mol_freedownloads.pdf.

Aubert, A.; DuQue, E.; VAlls, R. y FISAS, M. (2004) Dialogary transformar: Pedagogía crítica del siglo XXI. Barcelona, Graó.

BARDIn, L. (1986) El análisis de contenido. Madrid, Akal/Universitaria.

Berti, G. I. (2009) Pioneros del graffiti en España. Valencia, Editorial de la UPV.

BerTi, G. I. (2010) Práctica cultural comunitaria. El hip hop. Departamento de Filosofía, Universidad Autónoma de Barcelona. https://www.educacion.gob.es/teseo el 11 de julio de 2013.

BociXa ReI, X. (2004) A música acalada: hip hop galego. Tempos novos, 88, 60-63.

Bourdieu, P. (1997) Capital cultural, escuela y espacio social. Madrid, Siglo Veintiuno.

CARide Gómez, J. A. (2012) Tiempos educativos, tiempos de ocio. Monográfico. Pedagogía social. Revista interuniversitaria. 20, 7-16.

http://dx.doi.org/10.7179/PSRI_2012.20.p

CARnACEA, Á. y CÁmbara, A. (2011) Arte, Intervención y Acción social. La creatividad transformadora. Madrid, Editorial Grupo 5.

Chang, J. (2000) A chispeante odisea do hip-hop. Correo da Unesco, agosto-septiembre, 23-25.

Elola, J. (2008) La base americana contagió el "rap". El País. Consultado el 18 de mayo de 2013.

http://elpais.com/diario/2008/05/25/cultura/1211666402_850215.html.

Fraga, X. (2000) Vinte anos de hip hop. Unión libre. Cadernos de arte e cultura, 5, 139-142.

Freire, P. (2003) Pedagogía del oprimido. Buenos Aires, Siglo XXI.

Freire, P. (2009) Pedagogía de la autonomía: saberes necesarios para la práctica educativa. México, Siglo XXI.

García Amilburu, M. y García Gutiérrez, J. (2012) Filosofía de la educación, cuestiones de boy y de siempre. Madrid, Narcea.

García-Carpintero Muñoz, M. ${ }^{a}$ Á. (2009) Comportamientos de riesgo en adolescentes y jóvenes de la cultura hip hop. Un desafio a la atención enfermera. Departamento de Enfermería, Universidad de Sevilla.

https://www.educacion.gob.es/teseo el 11 de julio de 2013.

Giadés, M. (2005) Cine, rap, hip-hop: a cultura dera a alarma. Tempos novos, 103, 47-49.

GÓmez, J.; Latorre, A.; SÁnchez, M. y Flecha, R. (2006) Metodología comunicativa crítica. Barcelona, El Roure Ciencia.

Gonçalves de Paula, P. D. (2006) Graffiti hip hop femenino. La singularidad como significancia. Departamento de Pintura, Universidad Politécnica de Valencia. Tesis doctoral. Consultado en https://www.educacion.gob.es/teseo el 11 de julio de 2013.

Groys, B. (2005) Sobre lo nuevo. Ensayo de una economía cultural. Valencia, Pre-textos.

Hernández Serrano, M. J.; Jones, B. y González Sánchez, M. (2011) La generación Google. Evolución en las predisposiciones y comportamientos informativos de los jóvenes. Pedagogía Social. Revista Interuniversitaria, 18, 41-56. 
Marcos, C. (2010/03/24) El Madrid más «hip-hopero». El País. Consultado el 18 de mayo de 2013.

http://elpais.com/diario/2010/03/24/madrid/1269433466_850215.html.

Marcos del Cano, J. M. (2009) Vuelven los padres del rap español. Público. Consultado el 9 de abril de 2013.

http://www.publico.es/culturas/235398/vuelven-los-padres-del-rap-espanol.

Merriam, A. P. (2001) La música como cultura. Usos y funciones, en Cruces, Francisco y otros. Las culturas musicales. Lecturas de etnomusicología. Madrid, Trotta, 275-296.

Michels, U. (1982) Atlas de música, 1. Madrid, Alianza Editorial.

Mithen, S. (2007) Los neandertales cantaban rap. Los orígenes de la música y el lenguaje. Barcelona, Crítica.

Morduchowicz, R. (2008) Los jóvenes y las pantallas. Nuevas formas de sociabilidad. Barcelona, Gedisa.

Parmar, P. (2010) Does Hip Hop have home in Urban Education?, en SteInberG, Shirley R. 19 Urban Questions. Teaching in the City. New York, Peter Lang, 87-99.

Promusicae (2014) Mercado de la música grabada en España. Consultado el 18 de julio de 2014.

http://www.promusicae.es/estaticos/view/4-informes-promusicae.

REYES, F. J. (2003) Graffiti, breakdance y rap: el hip hop en España. Departamento de Comunicación audiovisual y publicidad I, Universidad Complutense de Madrid. Tesis doctoral.

https://www.educacion.gob.es/teseo el 11 de julio de 2013.

REYES, F. J. y El CHOJIN (2010) Rap. 25 años de rimas. Un recorrido por la bistoria del rap en España. Barcelona, Viceversa. 